\title{
Misassembled by Users
}

National Cancer Institute

\section{Source}

National Cancer Institute. Misassembled by Users. NCI Thesaurus. Code C79147.

Problem associated with incorrect assembly of a medical device or constituents by the users. 